\title{
A transgenic reporter mouse model for in vivo assessment of retinoic acid receptor transcriptional activation
}

\author{
Harald Carlsen ${ }^{1,2}$, Kanae Ebihara ${ }^{1}$, Nobuyo H. Kuwata', Kazuhisa Kuwata, \\ Gamze Aydemir ${ }^{3}$, Ralph Rühl ${ }^{3,4}$, and Rune Blomhoff ${ }^{1,5}$

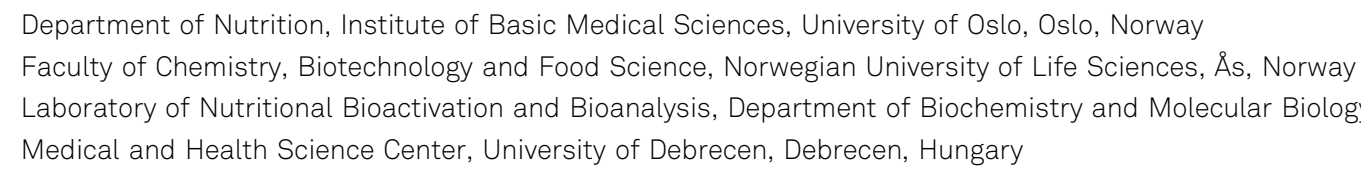

\begin{abstract}
Background: Vitamin A is essential for a wide range of life processes throughout embryogenesis to adult life. With the aim of developing an in vivo model to monitor retinoic acid receptor (RAR) transactivation real-time in intact animals, we generated transgenic mice carrying a luciferase (luc) reporter gene under the control of retinoic acid response elements (RAREs) consisting of three copies of a direct repeat with five spacing nucleotides (DR5). Methods: Transgenic mice carrying a RARE dependent luciferase reporter flanked with insulator sequence were generated by pronuclear injection. RARE dependent luciferase activity was detected by in vivo imaging or in tissue extracts following manipulations with RAR/retinoid X receptor (RXR) agonists, RAR antagonists or in vitamin A deficient mice. Results: We found a strong induction of luciferase activity in a time and dose dependent manner by retinoic acid as well as RAR agonists, but not by the RXR agonist (using $n=4-6$ per group; 94 mice). In addition, luciferase activity was strongly reduced in vitamin A-deficient mice ( $n=6-9 ; 30$ mice). These observations confirm that luciferase activity was controlled by RAR activation in the RARE-luc mouse. Luciferase activity was detectable in various organs, with high activity especially in brain and testis, indicating strong retinoid signalling in these tissues. Conclusion: The RARE-luc transgenic mice, which enabled real-time in vivo assessment of RAR activation, will be useful in understanding the normal physiology of vitamin A, the role of retinoid signalling in pathologies as well as to evaluate pharmacological ligands for RARs.
\end{abstract}

Keywords: Vitamin A, retinoic acid receptor, transgenic reporter mouse, luciferase, in vivo imaging

\section{Introduction}

Vitamin $\mathrm{A}$ is required throughout embryogenesis to adult life, and proper levels of vitamin A derivatives, called retinoids, are crucial for normal morphogenesis during embryonic development [1-4]. Retinoids are also indispensable throughout postnatal development for growth, reproduction, vision, maintenance of numerous tissues, and overall for survival $[5,6]$. The majority of the effects of retinoids are mediated by the binding of all-trans-retinoic acid (ATRA) as the endogenous retinoic acid receptors (RARs) ligand and 9-cis-13,14-dihydroretinoic acid (9CDHRA), as the endogenous ligand of the RXRs [7, 8]. These nuclear receptors, which all are transcription factors, consist of three related RARs (i.e. RAR $\alpha$, RAR $\beta$ and RAR $\gamma$ ) and three RXRs (i.e. RXR $\alpha, \operatorname{RXR} \beta$ and RXR $\gamma$ ). The RARs and RXRs form heterodimers that bind to retinoic acid receptor response elements (RAREs) in regulatory regions of target genes. Ligand binding leads to a conformational change in the heterodimer, causing a release of corepressors and recruitment of co-activators, which will promote induction of gene expression $[9,10]$.

During embryonic development, enzymes responsible for ATRA synthesis (e.g. ALDH1A (RALDH) 1-3) or degradation (e.g. CYP26A1-3) mainly generate localized gradients and distribution of ATRA. It appears that ALDH1A2 and CYP26A1 and 2 are the main players for controlling vitamin A signalling for normal patterning and organogenesis in the embryo [11-13]. Little is known about the main factors that are responsible for vitamin A signalling during 
adult life. Different from other nuclear receptor signalling systems, control of gene expression by vitamin A involves complexity at many different levels.

Briefly, dietary vitamin $\mathrm{A}$ is absorbed in the intestine, and transported to the liver where it is stored in the form of retinyl esters (REs). REs are hydrolysed to all-trans-retinol (ROH, vitamin A1 alcohol) and transported to the target tissues bound to a specific retinol-binding protein (RBP). In the target tissues, $\mathrm{ROH}$ is taken up and either transported back to plasma for recycling to other tissues or oxidized to ATRA to activate RARs-RXRs [14, 15]. The endogenous RXR ligand 9CDHRA, with the ability to synergistically co-activate the RAR-RXR heterodimers [7], seems to derive from a vitamin A1-independent pathway [16]. Furthermore, gene expression by RARs-RXRs is regulated by multiple transcriptional mediators (e.g. coactivators and corepressors) [7]. Since signal transduction of vitamin A is controlled at many different levels, such as absorption, uptake, storage, transport, metabolism and gene expression, appropriate animal models are necessary to resolve the complexity of its physiological regulation.

To assess spatio- and temporal RAR activation in vivo, RA-responsive reporter (RARE- $\beta$ galactosidase) mice have been generated. In these mice, however, reporter gene activity is detectable only in early stages embryos or sections dissected from the sacrificed animals [17, 18]. Some twenty years ago we and others demonstrated that it was possible to externally detect light produced by luciferase reporters in transgenic mice including NF- $\mathrm{\kappa B}$-luciferase reporter mice and EpRE-luciferase mice [19-28]. These unique reporter mice allow repeated dynamic measurements of the promoter activity over time in an individual mouse and permitted real-time observations of the consequences of a given treatment. By using this technology, we have generated transgenic reporter mice containing three copies of RARE, canonical DR5 sites derived from the RAR- $\beta 2$ promoter, coupled to the luciferase gene to monitor real-time RAR activation in living mice (RARE-luc mice).

This model has already been used in other studies to aid in understanding retinoid signalling in various physiological settings [29-35]. The present study is the first to report in more detail the main characteristics of the RARE-luc model and its utility for reporting on retinoid signalling. Detection of reporter activity can be achieved by in vivo luminescence imaging, ex vivo imaging or enzymatic assay, and immunohistochemistry. Strong induction of luciferase activity was observed after exposure to ATRA, and marked reduction was seen in the vitamin A deficient (VAD) RARE-luc mice. RAR agonist and antagonist treatments confirmed RAR dependency of the luciferase induction. The results presented here demonstrate that dynamics of RAR activation can be monitored close to real-time in living animals.

\section{Materials and methods}

\section{Materials}

Corn oil, Dulbecco's Modified Eagles Medium (DMEM), fetal bovine serum, L-glutamine, penicillin $(50 \mathrm{U} / \mathrm{ml})$ and streptomycin $(0.05 \mathrm{mg} / \mathrm{ml})$ stabilized solution were purchased from Sigma (St. Louis, MO). ATRA was from Fluka Biochemica (Buchs, Switzerland). Isoflurane from Baxter (Deerfield, IL) and D-luciferin was from Biothema (Dalarö, Sweden). LGD268 was obtained from Lilly Research Laboratories, CD271 was provided from by BIOMOL/Tebu-Bio (Boechout, Belgium), LGD268 was a gift from Ligand Pharmaceuticals (San Diego, CA), while AGN 194310 was generously donated by R. Chandraratna (Allergan, Irvine, CA). Based on supplier information the purity of the used substances was always $>99 \%$.

\section{DNA construction}

Three copies of RARE (DR5 cis element) derived from the RAR- $\beta 2$ promoter (5'-TCGACGGAAGGGTTCACCGAAAGTTCACTC-3' and the complementary strand 3'GCCTTCCCAAGTGGCTTTCAAGTGAGACT-5') were inserted into the XhoI site of pTAL-Luc (Promega, Madison. WI) to construct p3xRARE-Luc. A KpnI fragment from pNI-CD containing two copies of $\beta$-globin "core" fragment in AseI site of pNI were inserted into both KpnI site and blunted BamHI site of the p3xRARE-Luc to make transgene flanked with insulator core element [36, 37]. NotI-SalI fragment of the final construct was excised for microinjection.

\section{Generation of transgenic mice}

Transgenic mice were generated on C57BL $/ 6 \times$ CBA genetic background by standard procedures [38]. Briefly, fertilized zygotes were obtained from 4 weeks old superovulated C57BL/ $6 \times$ CBA females mated to C57BL/ $6 \times$ CBA males (age 8-12 weeks). Linearized DNA was injected into pronuclei of the zygotes. Zygotes were then transferred into the oviducts of pseudopregnant CD-1 mice. Luciferase positive founders were identified by PCR and crossed with C57BL/ 6 WTs to generate mice for testing of RARE mediated luciferase response following treatment with ATRA. The response to ATRA was assessed by in vivo imaging and biochemical analyses of luciferase activity in individual tissues. Based on these assessments one founder was selected for further breeding with C57BL/ 6 mice and analyses. All the mice used in this experiment were heterozygous for the transgene and back-crossed for more than six generations with C57BL/6 mice. 
Mice were housed in accordance with the guidelines of the Federation of European Laboratory Animal Science Associations, and animal experiment were done according to national guidelines for animal welfare (Norwegian Food Safety Authority; approval FOTS ID 2565). Mice had ad libitum access to water and standard chow if not otherwise stated. In total 124 mice were used in these experiments.

\section{Retinoid treatment}

Mice were gavage-fed ATRA $(50 \mathrm{mg} / \mathrm{kg}$ for time course assessment, and in the concentration dependency experiment; 1, 25, 50, 100, $200 \mathrm{mg} / \mathrm{kg}$ ) or the RAR-panagonist TTNPB $(0.05 \mathrm{mg} / \mathrm{kg}$, Sigma, Budapest, Hungary) dissolved in corn oil. Corn oil alone was given as control. CD271 (5 $\mathrm{mg} / \mathrm{kg}$; a synthetic RAR-ligand) and/or LGD268 ( $5 \mathrm{mg} / \mathrm{kg}$; a synthetic RXR-ligand) were administered in $25 \%$ aqueous Cremophor EL (Sigma, Budapest, Hungary) solution $(5 \mathrm{ml} / \mathrm{kg})$. In all the experiments mice were from 6 to 9 weeks of age.

\section{In vivo imaging and luciferase measurement}

In vivo imaging was performed using the IVIS 100 system and images analyzed by LivingImage software (Xenogen Corp/Perkin Elmer, Alameda, CA, USA). The IVIS 100 detects photons of light emitted from immobilised mice or tissues onto a cooled CCD camera. Following a single i.p. injection of D-luciferin $(120 \mathrm{mg} / \mathrm{kg}$; Biothema, Dalarø, Sweden) dissolved in $200 \mu \mathrm{l} \mathrm{PBS,} \mathrm{pH} \mathrm{7.8,} \mathrm{mice} \mathrm{were}$ anesthetized with a mixture of isoflurane gas and oxygen ( $3 \%$ isoflurane). Five minutes after luciferin administration, mice were placed in the CCD camera coupled light-tight chamber and gray-scale image of the animal was recorded. Photon emission was then integrated over a period of $1 \mathrm{~min}$ and recorded as pseudo-colour images. Gray-scale and pseudo-color images were merged to co-localize photon emission on animal body. Signal intensity was quantified as sum of all detected photon counts within the region of interests. Luciferase activity in the tissue and cell extracts were measured according to the manufacturer's instruction (Promega). The light intensity was related to protein concentration $(\mathrm{mg} / \mathrm{ml}$; Bio-Rad) and expressed as relative light units (RLU). The mice were housed in accordance with the guidelines of the Federation of European Laboratory Animal Science Associations (FELASA), and all animal experiments were performed according to national guidelines for animal welfare.

Experiments using CD271 and LGD268 were performed at the Laboratory Animal core facility of the University of Debrecen, Hungary in accordance with the National ethical guidelines of the Hungary. In vivo imaging was performed using Andor IQ imaging system and analysis was conducted with Andor IQ 1.6 evaluation software from Andor Technology (Belfast, UK).

\section{Cell experiments}

Cell experiments were performed with primary cultures of skin fibroblast isolated from the ears of new-born transgenic mice. Briefly, ears washed in $70 \%$ ethanol and in Hank's Balanced Salt Solution (HBSS, Gibco, Carlsbad, CA, USA) were cut into small pieces and transferred to new HBSS. Cells and pieces of tissue were centrifuged and pelleted at $1 \mathrm{~g}$. Supernatant was removed, and the pellet washed with HBSS. Pelleted material (explants) was then transferred to $75 \mathrm{~cm}^{2}$ tissue culture flask with $2 \mathrm{ml}$ DMEM (Gibco) with 50\% foetal calf serum and Glutamax (Gibco). Explants were cultured $\left(37^{\circ} \mathrm{C}, 5 \% \mathrm{CO}_{2}\right)$ until appearance of monolayers of fibroblasts surrounding the explants and medium was changed to DMEM with 10\% FCS. The cells were then cultured for approximately one week before the experiments with all-trans-RA and the RAR-pantagonist was performed. After treatment in various concentrations of all-trans-RA, with and without RAR-pan-antagonist for $24 \mathrm{~h}$, cells extracts were prepared and assayed for luciferase activity as described above. The RAR-pan-antagonist AGN 194310 was a kind gift from R. Chandraratna at Allergan (Irvine, CA). RA and RA-antagonists are sensitive to light, heat, and air in solution. A stock solution (about $0.01 \mathrm{M}$ ) of RA and antagonist were stored in 100\% ethanol. Solutions were stored under argon, in the dark and at $-70^{\circ} \mathrm{C}$. Concentration was determined periodically by spectrophotometry. Subsequent dilutions were made in growth medium with a final ethanol concentration of $0.1 \%(\mathrm{v} / \mathrm{v})$ which did not affect the described system. All cell culture experiments were performed in subdued light.

\section{Vitamin A deficient (VAD) mice}

RARE luciferase VAD mice were generated by feeding a VAD diet (C1016, Altromin, Lage, Germany) as described previously [39]. Briefly, offspring of RARE-luc dams who had been fed VAD diet from the onset of the gestation period were maintained on this diet for another four weeks after weaning, until weight difference was evident between VAD fed mice and age-matched mice fed control diet (C1000, Altromin) ( 10\% difference in weight on average). The status of vitamin A of the mice was determined by HPLC analysis of $\mathrm{ROH}$ and retinyl palmitate in liver. For HPLC analysis, ca. 5-10 mg liver tissue was homogenized in $90 \mu \mathrm{L}$ PBS, and $400 \mu \mathrm{L}$ isopropanol:aceton $(1: 1, \mathrm{v} / \mathrm{v})$ was added. The sample was vortexed for $5 \mathrm{~min}$ and centrifuged at $3656 \times \mathrm{g}$ at $+10^{\circ} \mathrm{C}$ for $15 \mathrm{~min}$. 
The supernatant $(80 \mu \mathrm{L})$ was used for HPLC analysis. Retinol and retinyl-ester determinations were performed on a YMC C-30 Carotenoid ${ }^{\circledR}$ column, $4.6 \times 250 \mathrm{~mm}$, $5 \mu \mathrm{m} \mathrm{dp}$. As a precolumn, supelcoguard LC-18 4.6× $20 \mathrm{~mm}$ was used. The mobile phase was composed of $5 \%$ water in acetonitrile for retinol analysis and 30\% dichloromethane in acetonitrile for retinyl ester analysis and was delivered isocratically at $2.0 \mathrm{~mL} / \mathrm{min}$. UV-detection was performed at $326 \mathrm{~nm}$.

\section{Graphical analysis}

Network graphical analysis was created using the mixOmics package in $\mathrm{R}$ (3.5 version) [41]. The resulting color codes for the mouse data as well as the food data were incorporated into a self-constructed graphic representation [40].

\section{Statistical analysis}

Results are shown as mean and standard error of mean. All statistical analyses were done using MS-Excel ttest function. Statistical significance was accepted at $\mathrm{p}<0.05$.

\section{Results}

\section{Generation of transgenic mice}

Initially, we tested the ability of $1 \mu \mathrm{M}$ ATRA to induce transcription of a variety of different RARE-luciferase constructs in P19 embryonic carcinoma cells (DR5-RARE derived from either RAR- $\beta 2$ promoter or the CYP26A1 promoter, one or multiple copies of the response elements, different directions, etc.) (data not shown). The construct used for generating transgenic mice consists of three RARE repeats, DR5 binding site derived from RAR- $\beta 2$ promoter [41], coupled to a TATA-box from the herpes simplex virus thymidine kinase (TK) promoter and the luciferase reporter gene, flanked with an insulator sequence [42]. It is well known that the expression of transgene driven by weak promoters may be heavily influenced by enhancers or silencers in the vicinity of the integration site of the transgene. In addition, methylation may extinguish their promoter activity gradually over long term. To overcome these concerns, two copies of a $250 \mathrm{bp}$ core fragment from "insulator" $\beta$-globin hypersensitive site 4 (HS4), flanked the transgene after ligation into both ends of the construct [42]. This insulator element is known to block interference from neighbouring enhancers and repress propagation of heterochromatin [43].

P19 embryonic carcinoma cells transfected with the construct showed a 20 -fold luciferase induction in $1 \mu \mathrm{M}$ ATRA for $24 \mathrm{~h}$ treatment, either with or without insulator (data not shown). Using the insulated and non-insulated RARE-luc constructs, a number of PCR based genotyping-positive mice were made. Notably, only mice containing the insulated construct had induced transgene expression by ATRA treatment. No ATRA inducible luciferase activity was obtained in any of the strains when we omitted the insulator sequence.

\section{RAR-dependent induction of luciferase expression}

The time-dependent induction of luciferase activity by ATRA and an RAR-pan-agonist TTNPB was measured in vivo with the IVIS imaging system. Since TTNPB is 1000-fold more teratogenic and toxic than ATRA, we applied a lower dose of TTNPB $(0.05 \mathrm{mg} / \mathrm{kg})$ to the mice $[44,45]$. After both $50 \mathrm{mg} / \mathrm{kg}$ ATRA and $0.05 \mathrm{mg} / \mathrm{kg}$ TTNPB treatment, maximal level of luminescence was reached at the $24 \mathrm{~h}$ time point, followed by a gradual decrease back to basal level in six days (Figure 1).

Next, we measured luciferase enzyme activity in tissue extracts. Variable, but still high levels of luciferase activity were found in all 16 tissues examined (Figure 2). Basal luciferase activity was highest in brain and testis, with 10- and 30-fold higher activity, respectively, compared to most other tissues. Induction by ATRA was between two to 11-fold in eye, thymus, lung, heart, liver, kidney, adipose tissue, muscle, bone, skin, ovary, uterus and epididymis. In brain, only marginal induction was observed, whereas no induction was found in testis.

Furthermore, we measured the kinetics of luciferase activity in tissue homogenates after ATRA treatment. Mice treated with increasing doses of ATRA $(1,25,50,100$, $200 \mathrm{mg} / \mathrm{kg}$ ) for $18 \mathrm{~h}$ exhibited a dose dependent induction of luciferase expression in lung, heart, liver, spleen and kidney (Figure 3). In lung, heart, spleen and kidney, induction of luciferase activity was detectable by the $25 \mathrm{mg} / \mathrm{kg}$ dose and increased further to its maximum at $100 \mathrm{mg} / \mathrm{kg}$. In liver luciferase activity reached a maximum at $200 \mathrm{mg} / \mathrm{kg}$ ATRA. Kinetic studies revealed that ATRAinduced luciferase activity peaked at $18 \mathrm{~h}$ after ATRA treatment $(50 \mathrm{mg} / \mathrm{kg})$ in lung, heart, spleen and kidney, whereas luciferase activity in liver peaked at $12 \mathrm{~h}$ in liver then decreased gradually. These data show that using the RARE-luc mouse, it is possible to detect RAR-RXR activation in time- and dose-dependent manner both in vivo and ex vivo.

\section{Activation of RXR does not activate luciferase expression}

The rexinoids are ligands that bind and activate the RXRs. The rexinoid LGD268 (also called LGD 100268 or 
A

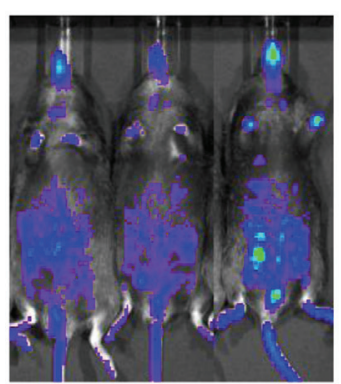

O h

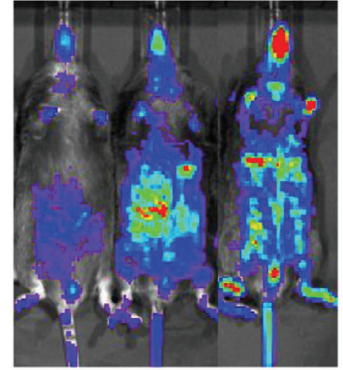

$24 \mathrm{~h}$

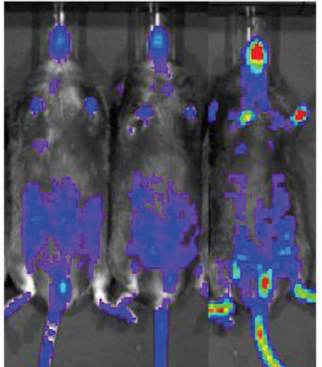

$48 \mathrm{~h}$

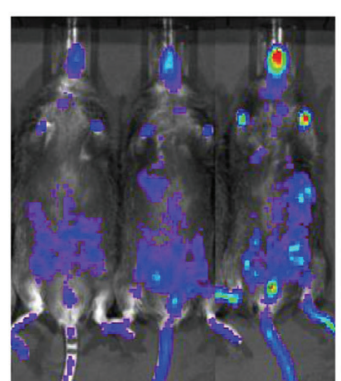

$72 \mathrm{~h}$
$0.05 \mathrm{mg} / \mathrm{kg}$ TTNPB

$50 \mathrm{mg} / \mathrm{kg}$ ATRA

CTRL

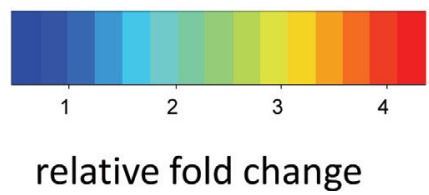

Figure 1. In vivo imaging of the transgenic mice treated with ATRA and RAR-pan-agonist TTNPB. (A) In vivo imaging of the transgenic mice treated with corn oil for control (left), $50 \mathrm{mg} / \mathrm{kg}$ ATRA (middle) and $0.05 \mathrm{mg} / \mathrm{kg}$ TTNPB (right) $24 \mathrm{~h}, 48 \mathrm{~h}, 72 \mathrm{~h}$, and 6 days after treatment in adult transgenic mice using the IVIS system. Intensity of photon flux is presented as a pseudo-colour image overlaid a gray-scale image of the animals. (B) Ratio between before and after ATRA or TTNPB treatment by quantification of the photon emission. Data are presented as a heat map of $n=6$ mice with a relative fold change color code added.

LG268) is a potent and specific ligand that binds solely to the RXRs, and not to the RARs [46]. We tested the ability of LGD268 to induce luciferase in the RARE-luc mouse. As a control, we used CD271 (also called Adapalene ${ }^{\mathrm{TM}}$ ), a synthetic retinoid analogue used in dermatological therapy $\left(\right.$ Differin $\left.^{\mathrm{TM}}\right)$ with a higher selectivity for $\operatorname{RAR} \beta$ and $\gamma$ [47].

Mice were administered orally with CD271 $(5 \mathrm{mg} / \mathrm{kg})$, LGD268 $(5 \mathrm{mg} / \mathrm{kg})$ or both, and sacrificed $16 \mathrm{~h}$ after the treatment. Figure 4 presents bio-imaging results for luciferase activity in various tissues. CD271 induced luciferase activity in brain, spleen, intestine, thymus, lung, white adipose tissues, heart, prostate/seminal vesicle complex, liver and kidney. LGD268 did not induce luciferase activity in any of the tissues examined. Combined treatments resulted in activities similar to the treatment with only CD271.

\section{Skin fibroblast retain the ATRA-inducible luciferase expression}

ATRA-inducible luciferase expression was examined in primary cultures of skin fibroblast isolated from the RARE-luc mice (Figure 5). To confirm that luciferase activity resulted from RAR-RXR activation, we exposed primary cultured cells to the RAR-pan-antagonist AGN 194310. The cells were treated for $24 \mathrm{~h}$ with increasing concentrations of ATRA $\left(10^{-9}-10^{-6} \mathrm{M}\right)$ or AGN $194310\left(10^{-8}-10^{-6} \mathrm{M}\right)$ in the presence of $10^{-7} \mathrm{M}$ ATRA. AGN 194310 blocked 
A

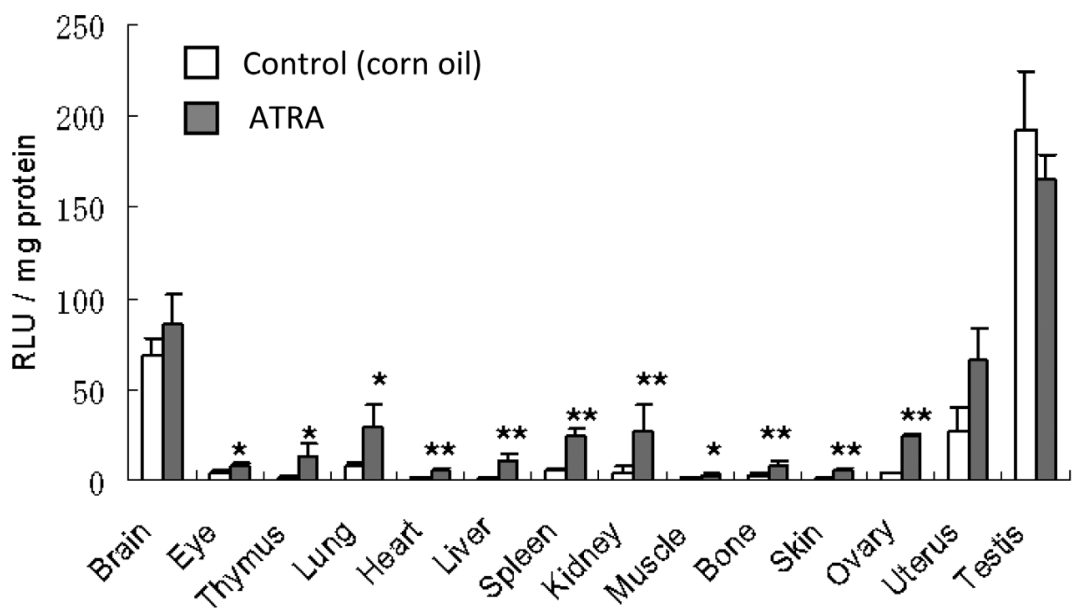

B

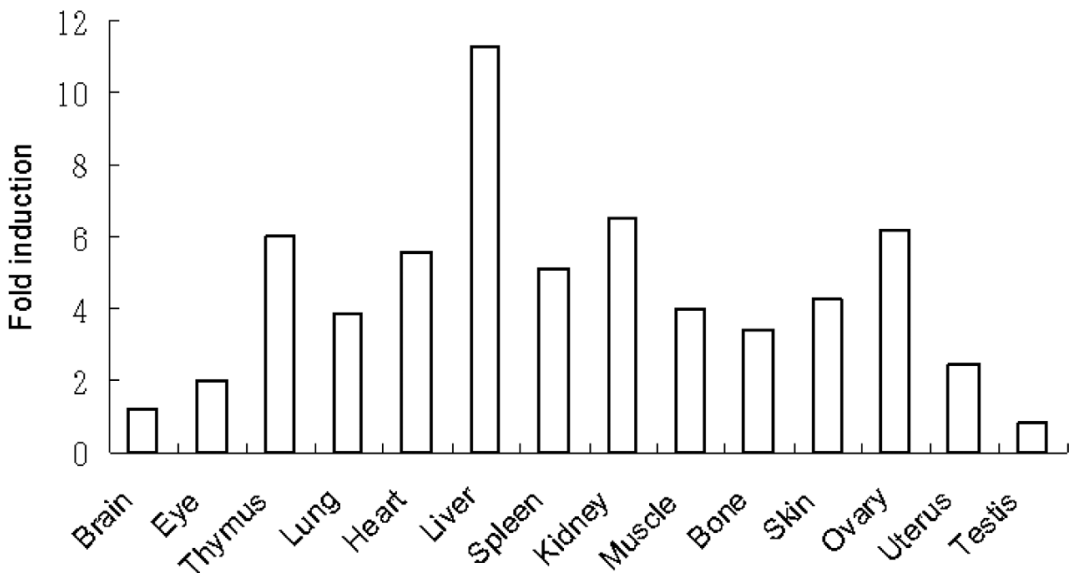

Figure 2. Luciferase expression in tissue extracts with and without ATRA treatment. (A) Mean luciferase expression in the selected tissues excised from control and ATRA treated mice (50 mg/kg $18 \mathrm{~h} ; \mathrm{n}=5)$. Error bars are SD. (B) Ratio of RLU between ATRA treated and control mice.

dose-dependent increase in luciferase activity by ATRA, indicating RAR-RXR activation by ATRA treatment.

\section{Decreased luciferase activity in vitamin A deficient diet fed mice (VAD) mice}

Luciferase activity was also measured in RARE-luc mice fed a vitamin A deficient diet (VAD). These VAD mice showed more than $60 \%$ reduction in luciferase activity compared to vitamin A sufficient diet fed control mice assessed by in vivo imaging (Figure 6). Twenty to eighty percent decrease was measured in tissue extract of eye, thymus, lung, heart, liver, spleen, kidney, muscle, bone, skin, ovary, and uterus (Figure 7). The activity was reduced by more than $90 \%$ in testis and epididymis. Intriguingly, luciferase activity in the brain was not decreased in VAD mice.

We next refed VAD mice with $50 \mathrm{mg} / \mathrm{kg}$ ATRA by oral gavage to evaluate the kinetics of RAR-RXR activation.
Luciferase activity was induced up to 10-15-fold in some organs after $6 \mathrm{~h}$, and it appeared to be time dependent (Figure $7 \mathrm{C}$ ). The induction was more rapid than in vitamin A sufficient diet fed mice, since no induction was detected as early as $3 \mathrm{~h}$ after $50 \mathrm{mg} / \mathrm{kg}$ ATRA treatment in vitamin A sufficient diet fed mice (data not shown). The induction level at $6 \mathrm{~h}$ in VAD mice is almost the same level as that at $18 \mathrm{~h}$ after ATRA treatment in vitamin A sufficient mice (Figure $3 \mathrm{~A}$ ). Thus, VAD mice are about 3-fold more sensitive to ATRA treatment compared with vitamin A sufficient mice.

\section{Discussion}

We have generated a novel transgenic mouse model that enables assessment of retinoic acid receptor-mediated signalling in intact living animals. The model has previously been used in various physiological settings 

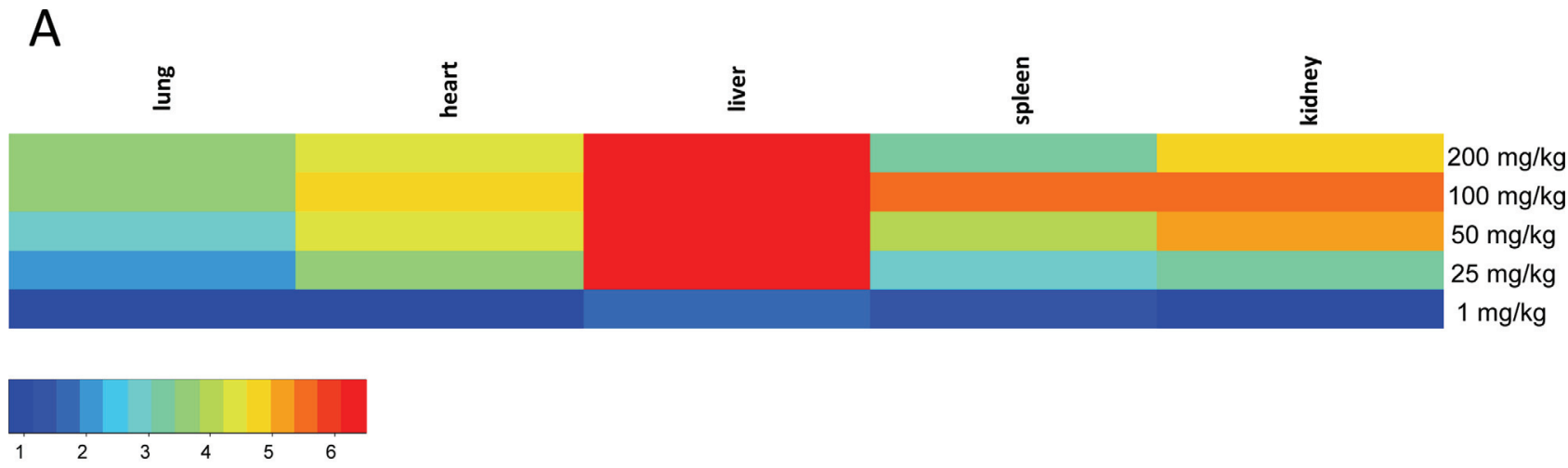

relative fold change
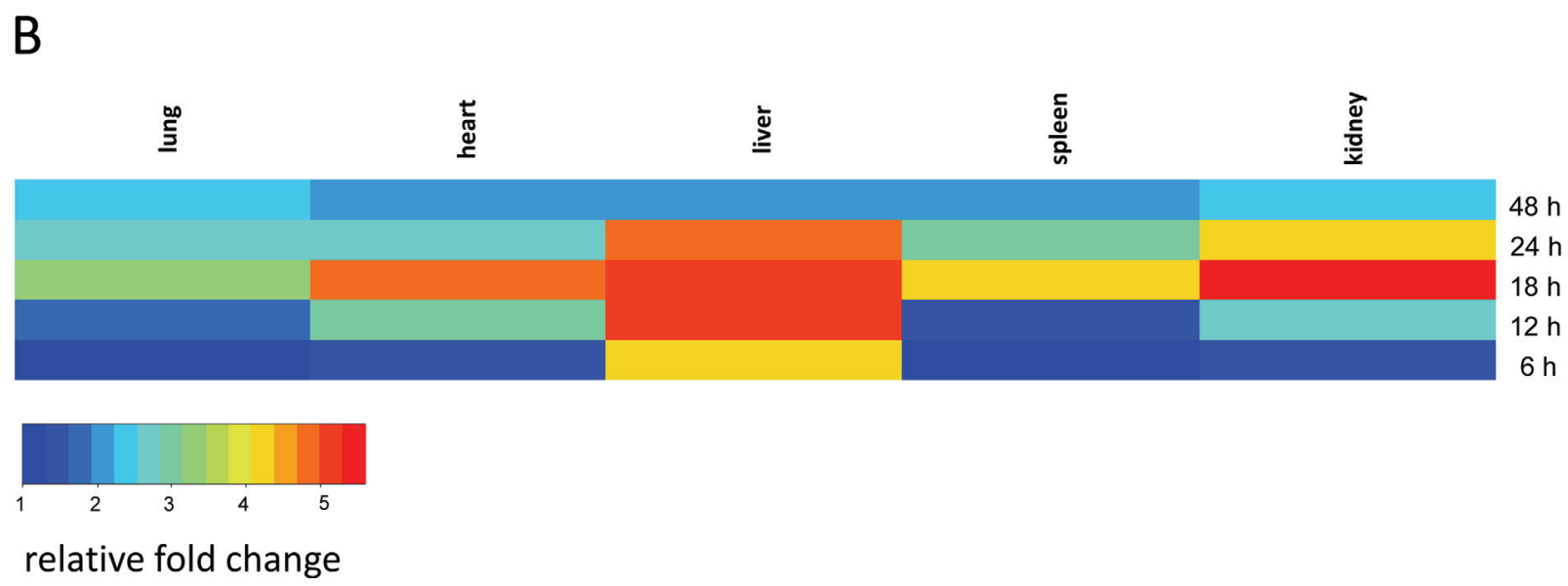

Figure 3. Time- and dose-dependent luciferase expression in tissue extracts. Ratio between luciferase expression in ATRA treated/control mice is presented. Presented as calculated heat maps with a color code for relative fold change. (A) Dose effect of ATRA treatment; $1 \mathrm{mg} / \mathrm{kg}, 25 \mathrm{mg} / \mathrm{kg}$, $50 \mathrm{mg} / \mathrm{kg}, 100 \mathrm{mg} / \mathrm{kg}$, and $200 \mathrm{mg} / \mathrm{kg}$ for $18 \mathrm{~h}(\mathrm{n}=5)$. Mean values are presented (B) Time course experiment in mice treated with $50 \mathrm{mg} / \mathrm{kg}$ ATRA for $6 h, 12 h, 18 h, 24 h$, and $48 \mathrm{~h}(n=5)$. Mean values are presented.

[29-31, 33-35, 48], but this is the first work to demonstrate in more detail the model's utility for reporting on retinoid signalling in a time dependent and tissue specific manner. In the RARE-luc transgenic mouse carrying three DR5elements coupled to the luciferase reporter gene, luciferase activity was first induced by ATRA in a dose- and timedependent manner. RAR-RXR agonists and RAR antagonist treatment confirmed the dependency of RAR transactivation for luciferase activity. Almost same levels of induction were detected by a low dose of TTNPB $(0.05 \mathrm{mg} / \mathrm{kg})$ and higher doses of ATRA $(50 \mathrm{mg} / \mathrm{kg}$ ), suggesting that TTNPB is 1000-fold more potent to activate RARs-RXRs than ATRA in vivo. The high potency of TTNPB to activate RAR may explain the fact that TTNPB is three orders of magnitude more toxic and teratogenic than ATRA. The RXR agonist LGD268 was not able to induce the luciferase signal in any of the tissues in the doses studied.

Among the tissues we examined, brain and testis exhibited 10-30-fold higher luciferase activity than other tissues. However, the luciferase activity was not induced by ATRA in these organs. Involvement of vitamin A in brain and testis has been studied in VAD and RAR disrupted animals. Infertility resulting from testis degeneration, a hallmark of VAD syndrome, is also evident in RAR $\alpha$ null mutant mice [49]. In addition, impairment of synaptic plasticity associated with learning and memory behaviours was observed in both VAD rodent and RAR $\beta-\mathrm{RXR} \gamma$ null mutant mice [50-52]. High activation in brain and testis observed in our 


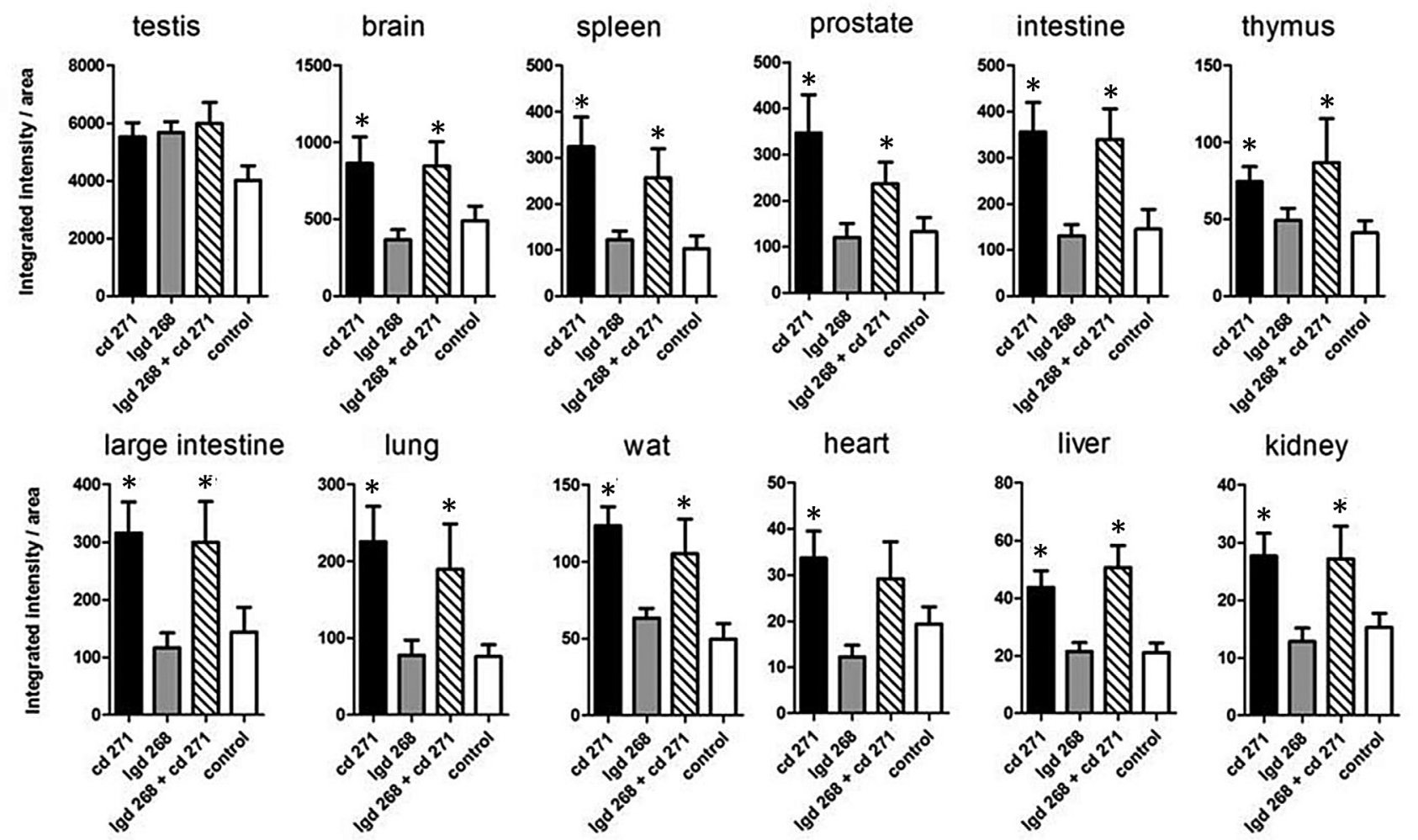

Figure 4. Luciferase expression in tissue extracts after administration of the RAR $\beta$ selective retinoid CD271 and the RXR selective rexinoid LGD268. Luciferase activity in the tissues excised from mice $(n=5)$ treated with CD271 ( $5 \mathrm{mg} / \mathrm{kg})$, LGD268 (5 mg/ $/ \mathrm{kg})$, combination or control. Error bars represent SEM and * represents statistical significance when $p>0.05$. WAT - white adipose tissue. Prostate sample includes prostate and seminal vesicular complex.
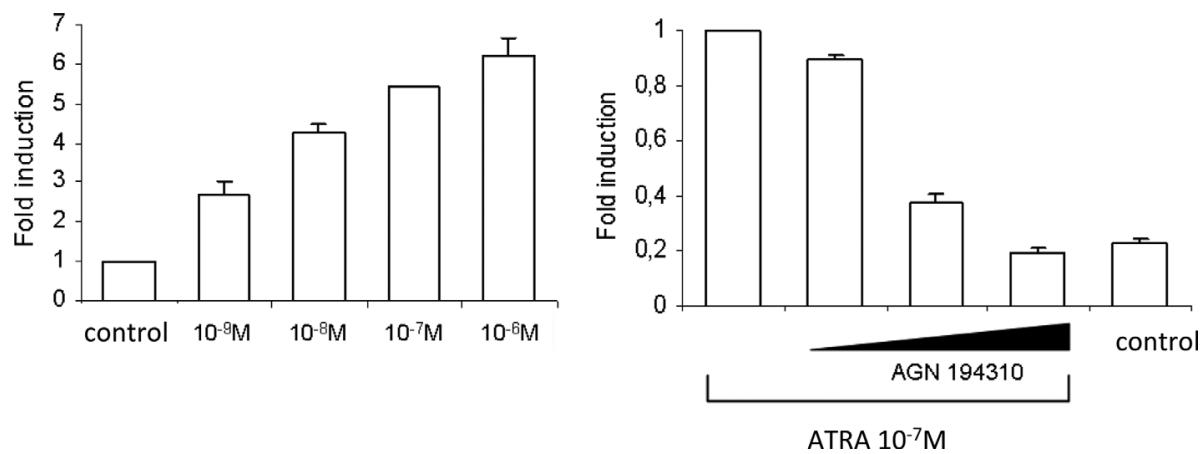

Figure 5. Expression of luciferase in skin fibroblast cells from transgenic mice. Cells were treated with increasing concentration of ATRA $\left(10^{-9}, 10^{-8}, 10^{-7}\right.$ or $\left.10^{-6} \mathrm{M}\right)$ or with RAR antagonist AGN $194310\left(10^{-9}, 10^{-8}\right.$ or $\left.10^{-7} \mathrm{M}\right)$ for $24 \mathrm{~h}$. Control cells were treated with same concentration of ethanol present in the retinoid solutions (0.005\%). Mean values \pm SD from three different experiments each done in triplicate are presented.

transgenic mice may reflect the importance of vitamin A signalling for normal reproduction and mature brain functioning. Immunohistochemistry showed strong luciferase expression in hippocampal neurons (data not shown). Our data clearly indicate an important function of vitamin ARAR-mediated signalling in the brain $[53,54]$ with a high importance for the survival and healthy maintenance of the mammalian organism. This importance is indicated by our data, that neither a significantly altered RAREsignalling during supplementation of a vitamin A deficient diet (Figure 7) nor during an RAR-ligand stimulation (Figures 2 and 4) can be observed.

At physiological plasma concentrations, ATRA cannot be taken up by testis, possibly owing to its inability to cross the 


\section{A}

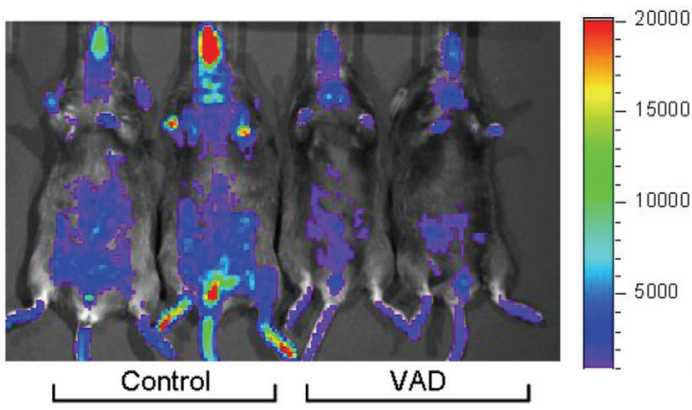

B

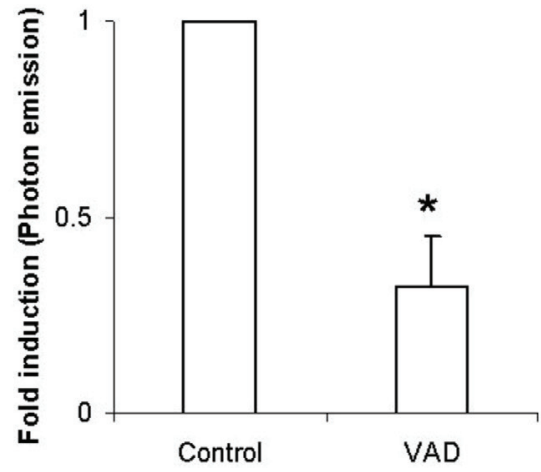

Figure 6. In vivo imaging of VAD transgenic mice. (A) In vivo imaging of the transgenic mice using the IVIS system. Intensity of photon flux is indicated by the pseudo-colour image. Left: 2 control mice, right: 2 VAD transgenic mice. (B) Ratio between control and VAD by quantification of the photon emission. The means are presented, and error bars are $S D,(n=6)$.

blood-testis barrier formed by Sertoli and peritubular cells; therefore testicular ATRA might be synthesized locally [55]. Sertoli cells are indicated as the main site of endogenous ATRA production in testis for normal spermatogenesis through the uptake of retinol from plasma RBP following oxidation of retinol to ATRA [56]. These observations suggest that the lack of ATRA mediated luciferase induction in testis may stem from the inability to take up ATRA from the circulation.

A supplementation with a vitamin A deficiency diet resulted in in $20 \%$ to $80 \%$ reduction of luciferase activity in most of tissues we examined in RARE-luc mice. More than $90 \%$ of the decrease was measured in male reproductive organs like testis and epididymis, whereas no decrease was observed in brain. Our result showing that luciferase activity was not modulated by either vitamin A excess or deficiency in brain, may suggest that high RAR activation is defended in brain despite various treatments and that reproductive organs are highly vulnerable to VAD.
Sensitivity to ATRA treatment varied according to nutritional vitamin A status. Our result show that vitamin A signalling was transduced 3-fold more rapid in VAD mice by ATRA replenishment compared to mice fed a control diet.

The strength of the RARE-luc transgenic mice is related to their ability to report real-time in vivo retinoic acid concentrations sufficient for driving a transcriptional activation. The use of luciferase as a reporter thus contrasts the LacZ reporter in RARE-LacZ reporter mice frequently used to assess RARE activation in tissues and cells excised from mice, particularly during the embryonic stages [18]. LacZ and the gene product $\beta$-galactosidase is excellent for detecting reporter activity in single cells but is not suitable for non-invasive assessments of RARE mediated transcription. Moreover, the luciferase has a relatively short half-life $(\sim 3 \mathrm{~h})$ compared to $\beta$-galactosidase $(\sim 48 \mathrm{~h})$, which allows a better temporal resolution of dynamic RARE regulation. The RARE-luc transgenic mice have been instrumental in understanding gut homing receptor expression on $\mathrm{T}$ cells [29, 34, 48, 57], embryonic lymph node development [33], $\mathrm{T}$ cell differentiation and immunity [30], carotenoid metabolism and function $[35,58]$, the role of ATRA signalling in tissue repair in postischemic hearts [31] as well as ATRA signalling in graft-versus-host disease [32] and the normal skin [59].

Every RARE may also be influenced by chromatin structure and dynamics, nearby regulatory DNA sequences as well as availability of activators, suppressors, coregulators and chaperone proteins (e.g. CRABP2), which can be regulated differently according to cell type. Care should therefore be taken when inferring transcriptional activation of retinoic acid responsive genes in vivo based on results of these mice. A complete picture of all these factors is needed to decipher the mechanisms controlling transcriptional regulation of retinoic acid responsive genes in vivo. Therefore, RARE activation will not necessarily reflect levels of endogenous ligands in tissues. For instance, levels of ATRA are approximately the same in liver and testis [60], but still the luciferase activity in non-treated mice is high in testis and virtually undetected in liver. This may have several explanations such as differences in the gene regulatory apparatus involved in RARE signalling as depicted above. For instance, CRABP2, which is important for transporting RA to the nucleus is highly expressed in testis $[61,62]$ and may therefore have significant impact on RA mediated signalling. Alternatively, other ligands besides ATRA can bind to RAR or RXR to elicit a transcriptional response that affects the DR5 driven luciferase activity. All-trans retinol [63], various alternative endogenous occurring retinoids [64, 65], DHA [66] and certain newly identified endogenous apo-carotenoids [67] are examples of ligands that have been identified as retinoic acid receptor agonists. 
A

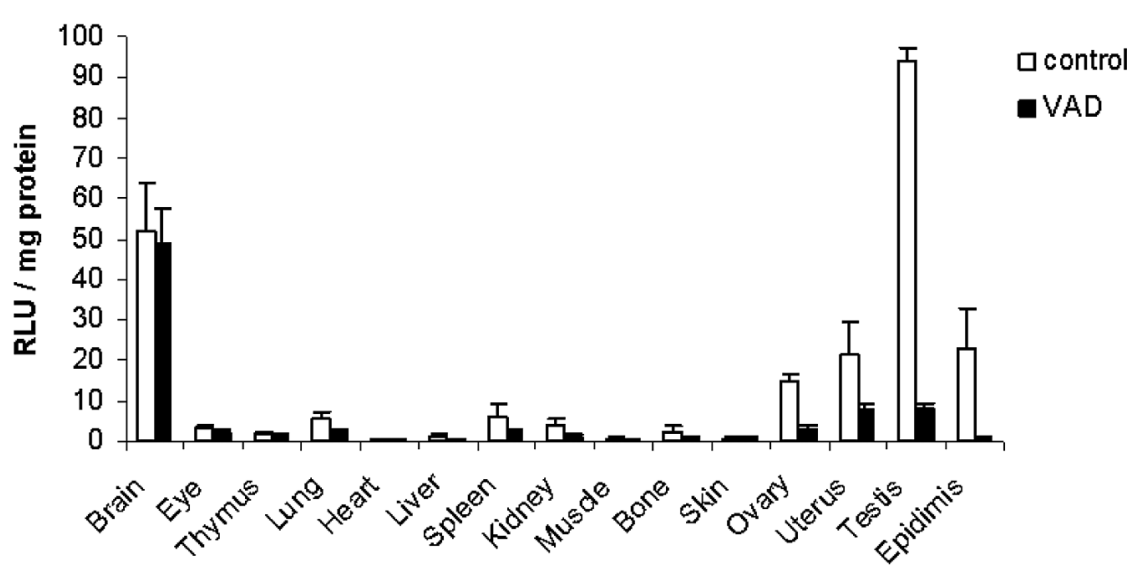

B

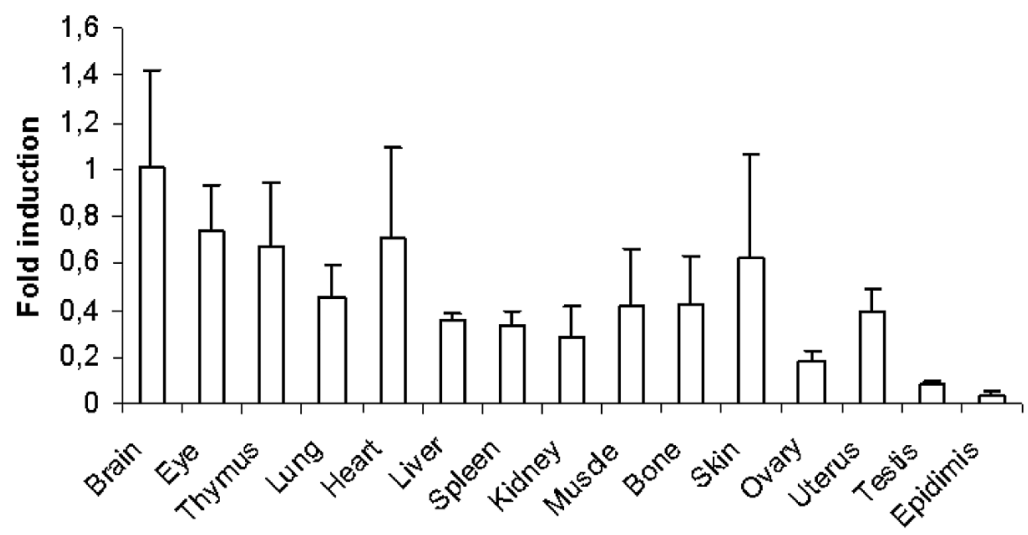

C

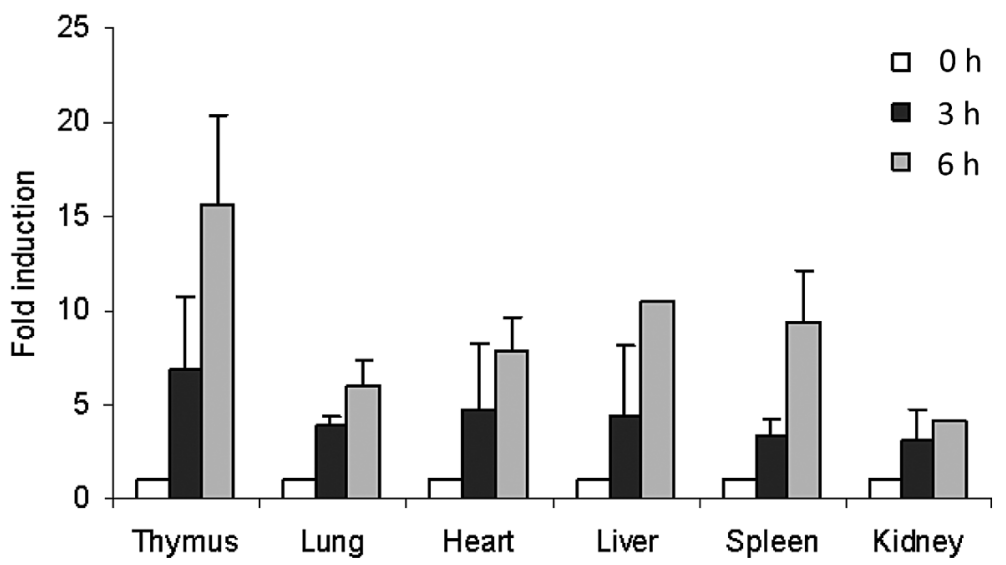

Figure 7. Luciferase expression in control and VAD transgenic mice tissue extracts (A) Luciferase expression in the selected tissue extracts excised from control and VAD mice $(n=9)$. (B) Ratio of RLU between tissues from control and VAD mice. The means presented. Error bars are SD. (C) Luciferase expression in VAD transgenic mice tissue extracts treated with $50 \mathrm{mg} / \mathrm{kg}$ RA for $3 \mathrm{~h}$ and $6 \mathrm{~h}$, $(\mathrm{n}=6)$. The means and SD from three different experiments using three (A and B) or two (C) mice each for control and VAD are presented.

In addition we speculate based on results in RARE-luc mice studies that lycopene might be a pro-vitamin A carotenoid $[35,68]$ via still non identified bio-active non ATRAmetabolites [69] and unpublished results.
Reporter mouse models have generated considerable interest related to the potential for improving and speeding up drug development [70]. Retinoids are currently applied to the treatment of some skin diseases and cancers 
[71, 72], but it is a huge interest in developing more sensitive and specific retinoids. Our novel transgenic mice can be a valuable tool for development of retinoid drugs, by identifying therapeutic targets, and measuring pharmacokinetics and toxicity of compounds. RXR, a partner of RAR to form a transcriptional unit, forms various heterodimers with other nuclear receptors. Therefore, crosstalk between vitamin A signalling and other signalling pathways can also be assessed in vivo. It is also interesting to study other factors or special conditions, such as disease and certain kinds of stresses that affect vitamin A signalling. The transgenic mouse generated in this study has great potential to resolve questions related to the complex regulation of vitamin A throughout life, from development to aging.

\section{References}

1. Balmer JE, Blomhoff R. Evolution of transcription factor binding sites in mammalian gene regulatory regions: handling counterintuitive results. J Mol Evol. 2009;68(6):654-64.

2. Duester $G$. Retinoic acid synthesis and signaling during early organogenesis. Cell. 2008;134(6):921-31.

3. Maden M. Retinoic acid in the development, regeneration and maintenance of the nervous system. Nat Rev Neurosci. 2007; 8(10):755-65.

4. Rochette-Egly C, Germain P. Dynamic and combinatorial control of gene expression by nuclear retinoic acid receptors (RARs). Nucl Recept Signal. 2009;7.

5. Blomhoff R, Green MH, Berg T, Norum KR. Transport and storage of vitamin A. Science. 1990;250(4979):399-404

6. Larange $A$, Cheroutre $H$. Retinoic acid and retinoic acid receptors as pleiotropic modulators of the immune system. Annu Rev Immunol. 2016;34:369-94.

7. Ruhl R, Krzyzosiak A, Niewiadomska-Cimicka A, Rochel N, Szeles L, Vaz B, et al. 9-cis-13,14-dihydroretinoic acid is an endogenous retinoid acting as RXR ligand in mice. PLoS Genet. 2015;11(6).

8. de Lera ÁR, Krezel W, Rühl R. An endogenous mammalian retinoid X receptor ligand, at last!. ChemMedChem. 2016; 11(10):1027-37.

9. Balmer JE, Blomhoff R. A robust characterization of retinoic acid response elements based on a comparison of sites in three species. J Steroid Biochem Mol Biol. 2005;96(5):347-54.

10. Laursen KB, Gudas LJ. Combinatorial knockout of RARalpha, RARbeta, and RARgamma completely abrogates transcriptional responses to retinoic acid in murine embryonic stem cells. J Biol Chem. 2018;293(30):11891-900.

11. Abu-Abed S, Dolle P, Metzger D, Beckett B, Chambon P, Petkovich $M$. The retinoic acid-metabolizing enzyme, CYP26A1, is essential for normal hindbrain patterning, vertebral identity, and development of posterior structures. Genes Dev. 2001;15(2):226-40.

12. Niederreither $K$, Subbarayan $V$, Dolle $P$, Chambon $P$. Embryonic retinoic acid synthesis is essential for early mouse post-implantation development. Nat Genet. 1999;21(4): 444-8.

13. Sakai Y, Meno C, Fujii H, Nishino J, Shiratori H, Saijoh Y, et al. The retinoic acid-inactivating enzyme CYP26 is essential for establishing an uneven distribution of retinoic acid along the anterio-posterior axis within the mouse embryo. Genes Dev. 2001;15(2):213-25.
14. Blomhoff R, Blomhoff HK. Overview of retinoid metabolism and function. J Neurobiol. 2006;66(7):606-30.

15. Blomhoff R, Green MH, Green JB, Berg T, Norum KR. Vitamin A metabolism: new perspectives on absorption, transport, and storage. Physiol Rev. 1991;71(4):951-90.

16. Ruhl R, Krezel W, de Lera AR. 9-Cis-13,14-dihydroretinoic acid, a new endogenous mammalian ligand of retinoid $X$ receptor and the active ligand of a potential new vitamin $A$ category: vitamin A5. Nutr Rev. 2018;76(12):929-41.

17. Mendelsohn C, Ruberte E, LeMeur M, Morriss-Kay G, Chambon P. Developmental analysis of the retinoic acidinducible RAR-beta 2 promoter in transgenic animals. Development. 1991:113(3):723-34.

18. Rossant J, Zirngibl R, Cado D, Shago M, Giguere V. Expression of a retinoic acid response element-hsplacZ transgene defines specific domains of transcriptional activity during mouse embryogenesis. Genes Dev. 1991;5(8):1333-44.

19. Carlsen H, Alexander G, Austenaa LM, Ebihara K, Blomhoff R. Molecular imaging of the transcription factor NF-kappaB, a primary regulator of stress response. Mutat Res. 2004;551(1-2): 199-211.

20. Carlsen H, Haugen F, Zadelaar S, Kleemann R, Kooistra T, Drevon CA, et al. Diet-induced obesity increases NF-kappaB signaling in reporter mice. Genes Nutr. 2009;4(3):215-22.

21. Carlsen H, Moskaug JO, Fromm SH, Blomhoff R. In vivo imaging of NF-kappa B activity. J Immunol. 2002;168(3): 1441-6.

22. Ciana P, Di Luccio G, Belcredito S, Pollio G, Vegeto E, Tatangelo $L$, et al. Engineering of a mouse for the in vivo profiling of estrogen receptor activity. Mol Endocrinol. 2001;15(7):1104-13.

23. Contag $\mathrm{CH}$, Bachmann $\mathrm{MH}$. Advances in in vivo bioluminescence imaging of gene expression. Annu Rev Biomed Eng. 2002;4:235-60.

24. Kielland A, Camassa LM, Dohlen G, Munthe LA, Blomhoff R, Amiry-Moghaddam M, et al. NF-kappaB activity in perinatal brain during infectious and hypoxic-ischemic insults revealed by a reporter mouse. Brain Pathol. 2012;22(4):499-510.

25. Kielland A, Carlsen $\mathrm{H}$. Molecular imaging of transcriptional regulation during inflammation. J Inflamm (Lond). 2010;7:20.

26. Moskaug JO, Carlsen H, Myhrstad M, Blomhoff R. Molecular imaging of the biological effects of quercetin and quercetinrich foods. Mech Ageing Dev. 2004;125(4):315-24.

27. Negrin RS, Contag $\mathrm{CH}$. In vivo imaging using bioluminescence: a tool for probing graft-versus-host disease. Nat Rev Immunol. 2006;6(6):484-90.

28. Zangani M, Carlsen H, Kielland A, Os A, Hauglin H, Blomhoff R, et al. Tracking early autoimmune disease by bioluminescent imaging of NF-kappaB activation reveals pathology in multiple organ systems. Am J Pathol. 2009;174(4):1358-67.

29. Villablanca EJ, Wang S, de Calisto J, Gomes DC, Kane MA, Napoli JL, et al. MyD88 and retinoic acid signaling pathways interact to modulate gastrointestinal activities of dendritic cells. Gastroenterology. 2011;141(1):176-85.

30. Pino-Lagos K, Guo Y, Brown C, Alexander MP, Elgueta R, Bennett KA, et al. A retinoic acid-dependent checkpoint in the development of CD4+ T cell-mediated immunity. J Exp Med. 2011;208(9):1767-75.

31. Bilbija D, Haugen F, Sagave J, Baysa A, Bastani N, Levy FO, et al. Retinoic acid signalling is activated in the postischemic heart and may influence remodelling. PLoS One. 2012;7(9).

32. Aoyama K, Saha A, Tolar J, Riddle MJ, Veenstra RG, Taylor PA, et al. Inhibiting retinoic acid signaling ameliorates graftversus-host disease by modifying T-cell differentiation and intestinal migration. Blood. 2013;122(12):2125-34. 
33. van de Pavert SA, Olivier BJ, Goverse G, Vondenhoff MF, Greuter M, Beke P, et al. Chemokine CXCL13 is essential for lymph node initiation and is induced by retinoic acid and neuronal stimulation. Nat Immunol. 2009;10(11):1193-9.

34. Jaensson-Gyllenback E, Kotarsky K, Zapata F, Persson EK, Gundersen TE, Blomhoff R, et al. Bile retinoids imprint intestinal CD103+ dendritic cells with the ability to generate gut-tropic T cells. Mucosal Immunol. 2011;4(4):438-47.

35. Aydemir G, Carlsen H, Blomhoff R, Ruhl R. Lycopene induces retinoic acid receptor transcriptional activation in mice. Mol Nutr Food Res. 2012;56(5):702-12.

36. Bell AC, West AG, Felsenfeld G. The protein CTCF is required for the enhancer blocking activity of vertebrate insulators. Cell. 1999;98(3):387-96.

37. Chung JH, Bell AC, Felsenfeld G. Characterization of the chicken beta-globin insulator. Proc Natl Acad Sci USA. 1997; 94(2):575-80.

38. Hogan B, Beddington R, Constantini F, Lacy E. Manipulating the mouse Embryo. (2nd ed). Plainview, NY: Cold Spring Harbor Laboratory Press; 1994.

39. Austenaa LM, Carlsen H, Ertesvag A, Alexander G, Blomhoff HK, Blomhoff R. Vitamin A status significantly alters nuclear factor-kappaB activity assessed by in vivo imaging. FASEB $\mathrm{J}$. 2004;18(11):1255-7.

40. R Core Team. R: A language and environment for statistical computing. https://www.R-project.org/R Foundation for Statistical Computing: Vienna, Austria; 2018.

41. de The H, Vivanco-Ruiz MM, Tiollais P, Stunnenberg H, Dejean Aldentification of a retinoic acid responsive element in the retinoic acid receptor beta gene. Nature. 1990;343(6254): $177-80$.

42. Chung JH, Whiteley M, Felsenfeld GA 5' element of the chicken beta-globin domain serves as an insulator in human erythroid cells and protects against position effect in Drosophila. Cell. 1993;74(3):505-14.

43. Ghirlando R, Giles K, Gowher H, Xiao T, Xu Z, Yao H, et al. Chromatin domains, insulators, and the regulation of gene expression. Biochim Biophys Acta. 2012;1819(7):644-51.

44. Benbrook DM, Madler MM, Spruce LW, Birckbichler PJ, Nelson EC, Subramanian S, et al. Biologically active heteroarotinoids exhibiting anticancer activity and decreased toxicity. J Med Chem. 1997;40(22):3567-83.

45. Kistler A, Galli B, Howard WB. Comparative teratogenicity of three retinoids: the arotinoids Ro 13-7410, Ro 13-6298 and Ro 15-1570. Arch Toxicol. 1990;64(1):43-8.

46. Boehm MF, Zhang L, Zhi L, McClurg MR, Berger E, Wagoner M, et al. Design and synthesis of potent retinoid $X$ receptor selective ligands that induce apoptosis in leukemia cells. J Med Chem. 1995;38(16):3146-55.

47. Ruhl R, Thiel R, Lacker TS, Strohschein S, Albert K, Nau H. Synthesis, high-performance liquid chromatography-nuclear magnetic resonance characterization and pharmacokinetics in mice of CD271 glucuronide. J Chromatogr B Biomed Sci Appl. 2001;757(1):101-9.

48. Wang S, Villablanca EJ, De Calisto J, Gomes DC, Nguyen DD, Mizoguchi E, et al. MyD88-dependent TLR1/2 signals educate dendritic cells with gut-specific imprinting properties. J Immunol. 2011;187(1):141-50.

49. Lufkin T, Lohnes D, Mark M, Dierich A, Gorry P, Gaub MP, et al. High postnatal lethality and testis degeneration in retinoic acid receptor alpha mutant mice. Proc Natl Acad Sci USA. 1993:90(15):7225-9.

50. Cocco S, Diaz G, Stancampiano R, Diana A, Carta M, Curreli R, et al. Vitamin A deficiency produces spatial learning and memory impairment in rats. Neuroscience. 2002;115(2): 475-82.
51. Etchamendy N, Enderlin V, Marighetto A, Pallet V, Higueret $P$, Jaffard R. Vitamin A deficiency and relational memory deficit in adult mice: relationships with changes in brain retinoid signalling. Behav Brain Res. 2003;145(1-2):37-49.

52. Misner DL, Jacobs S, Shimizu Y, de Urquiza AM, Solomin L, Perlmann $T$, et al. Vitamin A deprivation results in reversible loss of hippocampal long-term synaptic plasticity. Proc Natl Acad Sci USA. 2001;98(20):11714-9.

53. Wołoszynowska-Fraser MU, Kouchmeshky A, McCaffery P. Vitamin A and retinoic acid in cognition and cognitive disease. Annu Rev Nutr. 2020;40:247-72.

54. Olson CR, Mello CV. Significance of vitamin A to brain function, behavior and learning. Mol Nutr Food Res. 2010:54(4):489-95.

55. Kurlandsky SB, Gamble MV, Ramakrishnan R, Blaner WS Plasma delivery of retinoic acid to tissues in the rat. $J$ Biol Chem. 1995;270(30):17850-7.

56. Cavazzini D, Galdieri M, Ottonello S. Retinoic acid synthesis in the somatic cells of rat seminiferous tubules. Biochim Biophys Acta. 1996;1313(2):139-45.

57. Svensson M, Johansson-Lindbom B, Zapata F, Jaensson E, Austenaa LM, Blomhoff R, et al. Retinoic acid receptor signaling levels and antigen dose regulate gut homing receptor expression on CD8+ T cells. Mucosal Immunol. 2008;1(1):38-48.

58. Gouranton E, Aydemir G, Reynaud E, Marcotorchino J, Malezet C, Caris-Veyrat C, et al. Apo-10'-lycopenoic acid impacts adipose tissue biology via the retinoic acid receptors. Biochim Biophys Acta. 2011;1811(12):1105-14.

59. Mihaly J, Gericke J, Aydemir G, Weiss K, Carlsen H, Blomhoff R, et al. Reduced retinoid signaling in the skin after systemic retinoid-X receptor ligand treatment in mice with potential relevance for skin disorders. Dermatology. 2012; 225(4):304-11.

60. Obrochta KM, Kane MA, Napoli JL. Effects of diet and strain on mouse serum and tissue retinoid concentrations. PLoS One. 2014;9(6).

61. Rajan N, Kidd GL, Talmage DA, Blaner WS, Suhara A Goodman DS. Cellular retinoic acid-binding protein messenger RNA: levels in rat tissues and localization in rat testis. J Lipid Res. 1991;32(7):1195-204.

62. Zheng WL, Bucco RA, Schmitt MC, Wardlaw SA, Ong DE. Localization of cellular retinoic acid-binding protein (CRABP) II and CRABP in developing rat testis. Endocrinology. 1996; 137(11):5028-35.

63. Repa JJ, Hanson KK, Clagett-Dame M. All-trans-retinol is a ligand for the retinoic acid receptors. Proc Natl Acad Sci USA. 1993;90(15):7293-7.

64. Achkar CC, Derguini F, Blumberg B, Langston A, Levin AA, Speck J, et al. 4-Oxoretinol, a new natural ligand and transactivator of the retinoic acid receptors. Proc Natl Acad Sci USA. 1996;93(10):4879-84

65. Pijnappel WW, Hendriks HF, Folkers GE, van den Brink CE, Dekker EJ, Edelenbosch C, et al. The retinoid ligand 4-oxoretinoic acid is a highly active modulator of positional specification. Nature. 1993;366(6453):340-4.

66. de Urquiza AM, Liu S, Sjöberg $M$, Zetterström RH, Griffiths W, Sjövall J, et al. Docosahexaenoic acid, a ligand for the retinoid $X$ receptor in mouse brain. Science. 2000; 290(5499):2140-4.

67. Aydemir G, Domínguez M, de Lera AR, Mihaly J, Törőcsik D, Rühl R. Apo-14'-Carotenoic Acid Is a Novel Endogenous and Bioactive Apo-Carotenoid. Nutrients. 2019;11(9).

68. Aydemir G, Kasiri Y, Bartók EM, Birta E, Fröhlich K, Böhm V, et al. Lycopene supplementation restores vitamin A deficiency in mice and possesses thereby partial pro-vitamin A activity transmitted via RAR signaling. Mol Nutr Food Res. 2016; 60(11):2413-20. 
69. Aydemir G, Kasiri Y, Birta E, Béke G, Garcia AL, Bartók EM, et al. Lycopene-derived bioactive retinoic acid receptors/ retinoid- $X$ receptors-activating metabolites may be relevant for lycopene's anti-cancer potential. Mol Nutr Food Res. 2013;57(5):739-47.

70. Maggi A, Ciana P. Reporter mice and drug discovery and development. Nat Rev Drug Discov. 2005;4(3):249-55.

71. Altucci L, Gronemeyer $\mathrm{H}$. The promise of retinoids to fight against cancer. Nat Rev Cancer. 2001;1(3):181-93.

72. Zouboulis CC. Retinoids - which dermatological indications will benefit in the near future? Skin Pharmacol Appl Skin Physiol 2001;14(5):303-15.

\section{History}

Received October 29, 2020

Accepted March 31, 2021

Published online April 30, 2021

\section{Acknowledgement}

We are grateful to the animal care takers at the Department of Comparative Medicine, University of Oslo for their contribution. We thank G. Felsenfeld for providing us with the insulator plasmid and R. Chandraratna for providing the AGN 194310.

\section{Conflict of interest}

The authors declare that there are no conflicts of interest.

\section{Author contributions}

KE generated the construct and did most of the experiments and wrote the draft for the article. HC: designed experiments, participated in experiments, wrote article, NHK: Animal experiments. KK: Animal experiments. GA: Animal experiments with CD271 and LGD268. RR: Designed experiments, wrote article. RB: conceived the idea, designed experiments and wrote article.

\section{Funding}

This work was supported by grants from The Norwegian Cancer Society, The Research Council of Norway and the Throne Holst Foundation.

\section{ORCID}

Harald Carlsen

(iD) https://orcid.org/0000-0001-5123-5756

\section{Harald Carlsen}

Faculty of Chemistry

Biotechnology and Food Science

Norwegian University of Life Sciences

Christian Magnus Falsens vei 1

1433 Ås

Norway

harald.carlsen@nmbu.no 